\title{
Balades, lais i rondells francesos en la literatura catalana del segle $\mathrm{Xv}^{*}$ Marta Marfany Simó
}

« [...] los françeses [...] ponen sones [...] a las sus obras, e cántanlas por dulçes e diversas maneras, e tanto han familiar, açepta e por manos la música, que paresçe que entr'ellos ayan nasçido aquellos grandes philósofos Orfeo, Pitágoras e Empédocles [...].»

Marquès de Santillana, Prohemio (Rohland 1997: 21)

S'ha destacat sovint la importància de la cultura francesa a la Corona d'Aragó durant la segona meitat del segle XIV, sobretot a partir del matrimoni el 1380 de Joan d'Aragó (1350-1396) i Violant de Bar (c. I365|43I). Gràcies a la documentació conservada, sabem que la parella reial tenia un autèntic desfici pels llibres, amb interessos culturals molt amplis (història, autors clàssics, ciència, música, literatura...), i una especial predilecció per tot el que era francès. Tots dos monarques tingueren un paper decisiu en la circulació de textos poètics francesos: per exemple, el 1383 Violant obtingué a través del seu oncle, el duc de Berry, un Roman de la Rose, i el 1389 rebé del seu cosí, el comte de Foix, un còdex de Machaut.

Músic i poeta, Guillaume de Machaut (c. 13001377) marcarà el rumb de la poesia francesa tardomedieval i, com a màxim representant de l'Ars nova, té el privilegi, destinat a molt pocs compositors, d'ocupar un lloc clau en la història de la música occidental. Machaut era, en efecte, un dels autors admirats a la cort d'Aragó: el 1380 l'infant Joan demana a la seva sogra, duquessa de Bar, un «romanç de Ma-

\footnotetext{
* Aquest article s'inscriu en el projecte FFI2008-05556-C03-02 del MCel. Voldria donar les gràcies a Maricarmen Gómez Muntané per la revisió que va fer d'aquest treball, que l'ha millorat considerablement, i per tot el que m'ha ensenyat sobre música medieval. També voldria agrair les aportacions que hi han fet L. Cabré, M. Cabré, S. Martí,J. Pujol, F. Rodríguez Risquete i J.Torró. Els errors que hi pugui haver són només meus.
}

chaut», i diverses cartes de Violant entre 1386 i 1390 ens presenten una reina lectora de Machaut i posseïdora de llibres seus. Machaut és també un dels autors representats encara al manuscrit de Chantilly (Musée Condé de Chantilly, 564, olim 1047), un dels repertoris més importants de música polifònica francesa del segle XIv i la font principal de l'Ars subtilior. Aquest estil musical, derivat de l'Ars nova francesa, neix i es desenvolupa sobretot en tres corts meridionals: la cort papal d'Avinyó, la dels reis d'Aragó (la cort de Pere III i sobretot la de Joan I) i la cort del comte de Foix (1378-1394). És amb aquestes corts que es relacionen diversos compositors i peces del manuscrit de Chantilly, especialment amb la cort de Joan I, tot i que el còdex no en procedeix directament.'

Gràcies sobretot als treballs de Maricarmen Gómez Muntané, coneixem amb força precisió la música a la cort d'Aragó durant aquest període: sabem que hi tenia un paper essencial per tradició i que des de Pere III rebé una forta influència francesa, dominant sota el regnat de Joan I. Mecenes de músics, ell mateix compositor aficionat, per la cort de Joan I desfilaren els ministrers i chantres més brillants de l'època, alguns dels quals continuaren al servei de Martíl i de Martí el Jove a Sicília. L'Ars nova i després l'Ars subtilior eclipsaren la tradició trobadoresca, i les noves formes musicals -sobretot balades i rondells-foren les

\footnotetext{
I. Vegeu, en aquest mateix número de Mot so razo, l'article de Maricarmen Gómez Muntané (2009).
} 


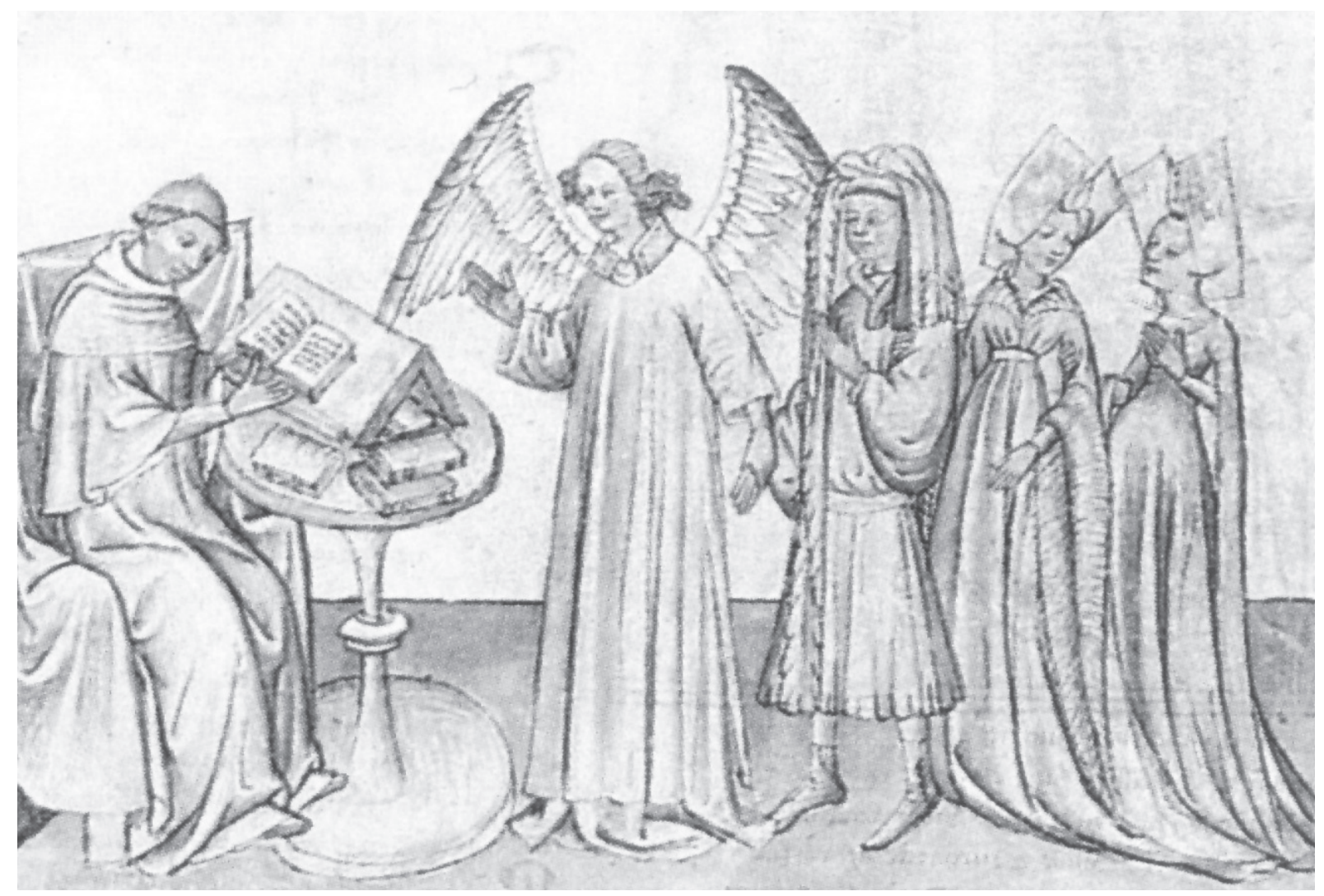

Guillaume de Machaut amb un àngel i les al legories Afecte, Plaer i Esperança (Pierpont Morgan Library, 396, f. Iv).

més emprades pels compositors dels segles XIV i XV a França i també a la Corona d'Aragó.

No és d'estranyar que aquestes formes d'origen musical -lai, virelai, rondell i balada- traspassessin a la poesia catalana ni que el primer poeta que sabem que adaptà el lai a la tradició pròpia fos Andreu Febrer, escrivà de Joan I i de Martí l, després camarlenc de Martí el Jove i documentat al servei de Violant de Bar entre 1410 i 1413; a més, en l'exercici d'aquests càrrecs reials, Andreu Febrer féu diversos viatges a França (Parera 2006: 5-13). Tampoc sorprèn, doncs, que el lai d'Andreu Febrer Amors, qui tost fér, quant li play tingui ressons clars del lai de Machaut, Loyauté, que point ne delay. No sabem fins a quin punt Febrer havia llegit i escoltat l'obra de Machaut, però «amb el coneixement, almenys, de Loyauté, que point ne delay en va tenir prou per ampliar l'espai de la lírica cortesana pròpia» (Cabré 2007: 105). L'adaptació del lai a la poesia catalana ha estat estudiada per Cabré (1986 i 1987), que descriu amb detall el procés d'assimilació d'aquesta forma, en el qual intervenen la tradició pròpia de la cançó i el descord i l'estampida trobadorescos, a més del trobar ric de Cerverí de
Girona. Les primeres mostres catalanes de balades són també d'autors en actiu al tombant de segle: d'Andreu Febrer, com per al lai, i també de Gilabert de Pròixida, documentat com a talladorer de Joan I, cambrer de Martí I després i vinculat a la cort papal d'Avinyó (Alberni 2005, Riera 2008). Per determinar l'abast de la influència francesa en la poesia catalana de finals del segle XIV, però també en la del segle $X V$, la música és un factor imprescindible, sense el qual tindríem una visió esbiaixada del fenomen.

En efecte, al tombant de segle, la música i la poesia franceses continuaran en voga a la Corona d'Aragó. L'obra anònima Frondino e Brisona, per exemple, conté un virelai i cinc rondells en francès. És una narració en noves rimades occitanes que intercala, a més de les peces franceses, cartes en prosa en català, i per això es pot considerar que segueix el model dels livres francesos: amb el nom de livre, es designava aquelles obres que combinaven el dit narratiu en versos apariats amb cartes en prosa i poemes intercalats -rondells, balades, lais i virelais-, un gènere que proliferarà a França a partir del Livre du voir dit de Guillaume de Machaut. L'autor anònim de Frondino e Brisona adapta 
el model dels livres segons el codi lingüístic propi del seu context literari: les noves rimades en occità, la prosa en català i les cançons en francès.

El cançoner català Vega-Aguiló (Barcelona, Biblioteca de Catalunya, 7 i 8) és un altre valuós testimoni dels gustos literaris dels primers anys del segle $\mathrm{XV}$ : conté poesia trobadoresca clàssica, autors catalans del segle XIV i principis del XV -hi destaquen Gilabert de Pròixida i Andreu Febrer-, noves rimades i un recull de vint-i-tres poemes francesos. Aquesta petita antologia francesa, en la qual hi és representat testimonialment Guillaume de Machaut, està centrada en la figura d'Oton de Grandson (c. 1345-1397). El marquès de Santillana descriu Grandson al Prohemio com un poeta que destacà, igual que Machaut, en l'art de la música («se uvo alta e dulçemente en esta arte»), si bé no es coneix cap peça seva musicada. Sigui com sigui, els seus poemes deixaran traces en l'obra de
Christine de Pizan i d'Alain Chartier, i també en la de l'anglès Geoffrey Chaucer. Queda per fer l'estudi de la influència de Grandson en la poesia catalana, que de ben segur donarà resultats importants: fins ara, se n'han trobat mostres en l'obra de Jordi de Sant Jordi (Torró 2007: 826) i en la de Pere Torroella (Rodríguez Risquete en premsa), dos poetes molt allunyats en el temps (quan va morir Jordi de Sant Jordi el 1424, Pere Torroella no feia gaire que havia nascut) però que tenen en comú haver adaptat les formes fixes franceses.

La presència de la lírica francesa al Vega-Aguiló i, per extensió, les traces de la seva circulació en terres catalanes no s'aturen aquí. En un altre text copiat en aquest manuscrit, les noves rimades Procés de Corona d'aur contra en Bertran Tudela de Francesc de la Via, s'hi esmenten dues composicions musicals en francès:

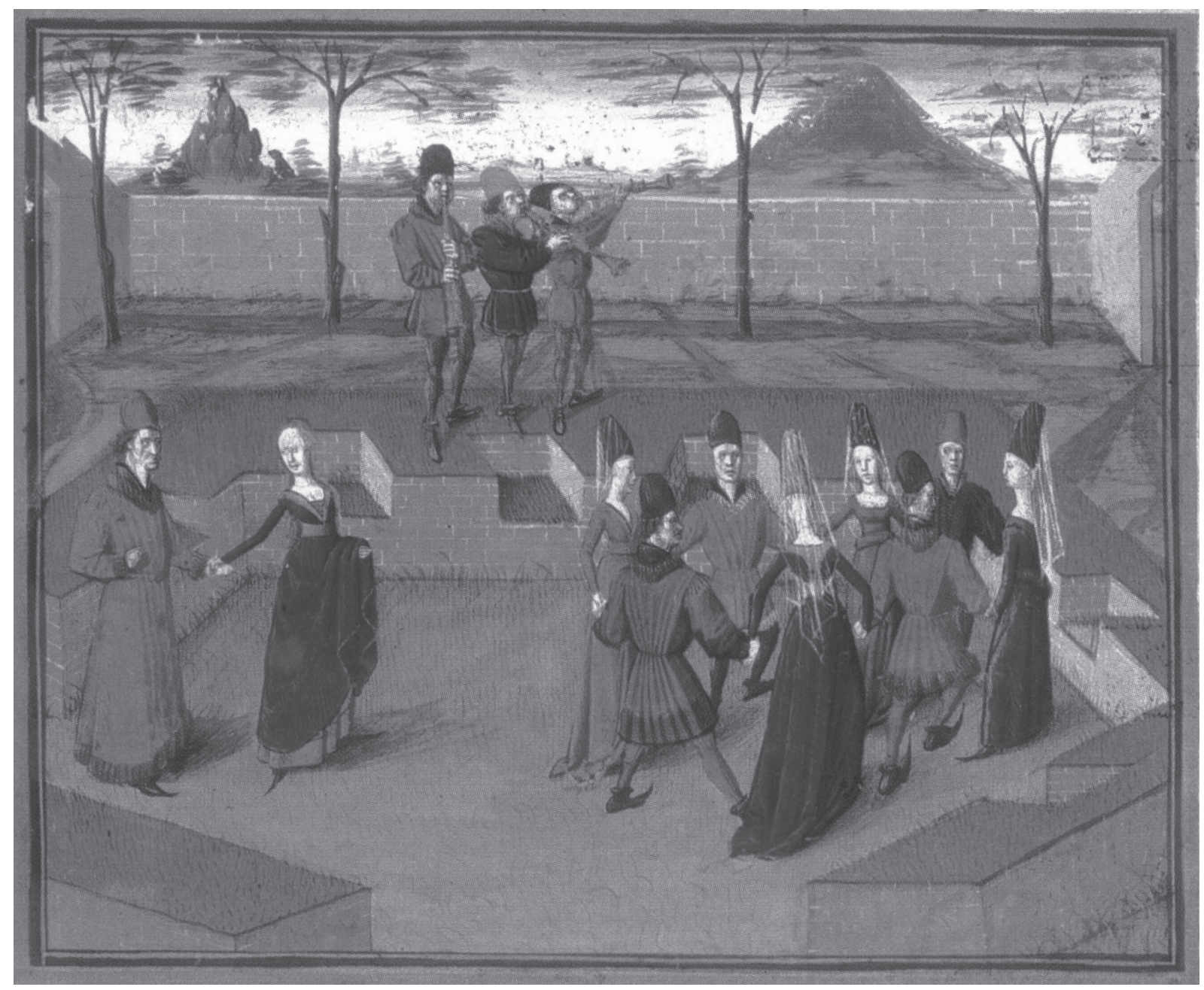

Tres ministrers acompanyen una dansa (Le Roman de la Rose: París, Bibliothèque de l'Arsenal, ms. 19153, f. 7; segle xv). 


\section{Polifonia: cant, tenor i contra}

Cant, tenor i contra (contratenor) eren termes per designar les diferents parts vocals d'una peça polifònica, que es cantaven simultàniament. És amb aquests termes que Joan I va descriure el rondell en francès que ell mateix havia compost: «nos, entrevenents alcuns dels nostres xantres, fahem I rondell notat ab sa tenor e contratenor e ab son cant» (Arxiu de la Corona d'Aragó, reg. 1658, f. 108, apud Gómez Muntané 1979: I, 200). A més dels versos del Procés de Francesc de la Via, en la poesia catalana del segle XV hi ha nombrosos exemples d'aquesta terminologia musical, que al ludeix a la polifonia a tres veus. En destaco només alguns:

A tots sos cants fas la tenor

ab la contra del qu'és millor.

Pere Torroella (Tant mon voler s'és dat a.mors, vv. 119-120)

Yo de mon cant no só fora d'acort, ne nn ma cançó no puch metra falcia; la nota $m$ fa tant bona companyia, contra, tenor, a tot ffa sser concort.

Joan Fogassot (Tençó amb Joan Puculull, Rao 67.12, vv. 66-68)

Al vostre dolç cant yo faça l'acort y axí serem tres fent gran armonia: aquells les grans contres, vos cant, yo tenor, sereu vos loat y aquells d'agonia sentran la greu pena y l'ànima mia haurà de tal música lo premi d'amor.

Bernat Fenollar (Lo passi en cobles, poema col lectiu, Rao 60.3, vv. 1263-1267)

Aquests exemples mostren el transvasament de la terminologia musical de l'època al llenguatge poètic.

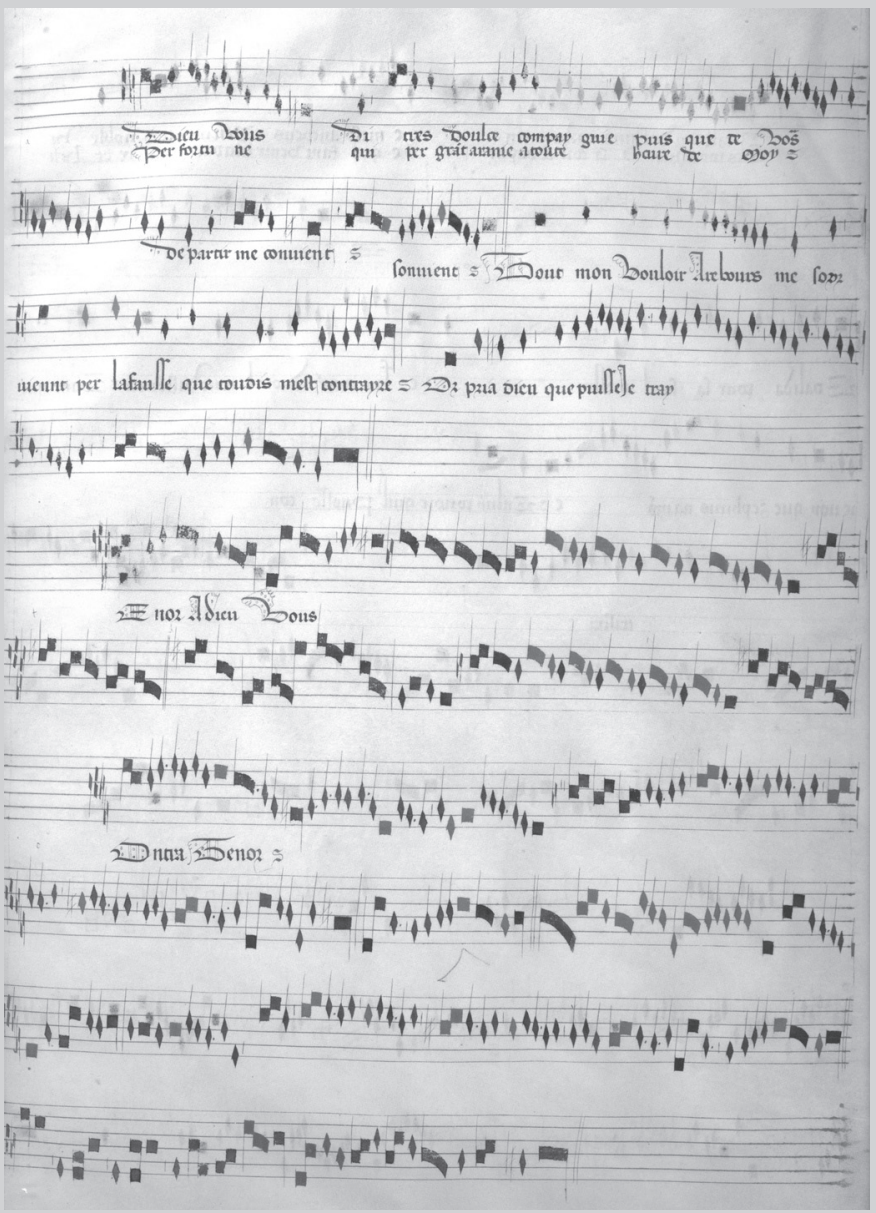

Adieu vous di (Manuscrit de Chantilly: Musée Condé de Chantilly, 564, olim 1047, f. 47). Polifonia a tres veus: la part on hi ha copiada la lletra és el cant; a sota, s'hi poden llegir els mots «[T]enor Adieu vous» $\mathrm{i}$ «[C] ontra Tenor», seguits de la música que correspon a cada veu. 
Ladonchs van començar

lo temps de baxa dança

d'una cançó de França

trop plasén per ausir:

«je l'am je vulh servir»,

ab molt graciós so;

(vv. II-16; Pacheco 1997: 159-160)

comenssàran cantar,

e gran joya manar

ab belh solaç e ris,

us cantar de París

mot graciós e gay:

"Cor e cors e quant que j'ay...»

E cant faray ma via

ab tant malodia?

A tres votz totz ensemps

ab tal compàs e temps

ab cant, contra, tenor

(vv. 639-649; Pacheco 1997: 189. Corregeixo la puntuació del v. 649)

El primer exemple ens mostra una escena de ball («Ladonchs van començar / lo temps de baxa dança», 'llavors va arribar l'hora de dansar'): el terme baixa dansa designava un tipus de dansa de ritme lent, mentre que en l'alta dansa el temps era més ràpid. La baixa dansa Je l'am je vulh servir devia ser monòdica, com la majoria de baixes danses. Pel que fa a la segona composició, Cor e cors e quant que j'ay, Francesc de la Via la presenta com una peça polifònica a tres veus: és a dir, cant, contra -contratenor - i tenor. El Procés de Corona d'aur, l'acció del qual se situa els mesos de maig i juny de 1406, és ple de referències a persones reals relacionades amb Francesc de la Via i d'alguns fets que es documenten aquell mateix any (Alberni 2007). Per tant, la dansa i la cançó polifònica citades devien estar de moda l'any 1406.

De fet, la presència musical francesa, que des del segle XIV, primer amb l'Ars nova i després amb l'Ars subtilior, dominava el panorama europeu, continuarà al llarg del segle Xv: a partir dels anys vint, els compositors de l'escola francoflamenca començaran un regnat musical que s'allargarà fins a finals de segle. Això vol dir que, excepte a Itàlia, durant més d'un segle el francès fou la llengua de la majoria de cançons profanes que sonaven a les corts europees. I aquest factor, com hem dit, cal tenir-lo ben present en l'estudi de la poesia catalana de l'època. Així, per exemple, el passatge del poema Cl d'Ausiàs March que reescriu dos versos del rondell Se onques deux yeulx d'Alain Chartier (1380/90-1430), ${ }^{3}$

Se onques deux yeulx orent telle puissance de donner dueil et de promettre joie

(Alain Chartier, XX, vv. 1-2)

Yo viu uns ulls haver tan gran potença de dar dolor e prometre plaher

(Ausiàs March, Cl, vv. I-2)

s'explica millor si tenim en compte l'estructura musical d'aquesta forma fixa, la més repetitiva de totes: els dos primers versos, la secció A del refrany, es repetien al final de la segona i de la tercera estrofa, per tant eren fàcils de recordar, sobretot si eren cantats. La música d'aquesta peça no s'ha conservat, però sí la d'un altre rondell d'Alain Chartier, Au feu, au feu, del qual Romeu Llull reprèn el primer vers de la secció $A$ del refrany al poema Requesta d'amor:

Au feu! Au feu! Au feu, qui mon cuer art

(Alain Chartier, XIX (rondeau), v. I)

Ah foch! A foch! Que d'amor tot me crem!

(Romeu Llull, IX, v. 14)

La música d'aquest rondell és anònima, però s'han conservat quatre rondells d'Alain Chartier amb música de Gilles Binchois (1400-1460), un dels compositors més importants de mitjan segle $x \mathrm{~V}$, de la primera generació de l'escola francoflamenca de la cort de Borgonya. De fet, la versió musical del rondell Triste plaisir et doloreuse joye d'Alain Chartier és «one of Binchois' most glorious achievements» (Fallows 2000: 209), i, juntament amb la versió musical de la balada Dueil angoisseux, rage desmesurée de Christine de Pizan (I364-c.|430), la balada VI de Les Cent Ballades, es poden considerar els èxits profans d'aquest compositor. Gràcies a l'excel lent treball de Jane Whetnall (2005), sabem que la versió musical de Gilles Binchois d'aquesta balada de Christine de Pizan era coneguda a la Corona d'Aragó a mitjan segle Xv. És la «cançó de l'angoixós» que esmenta Bernat Hug de Rocabertí

\footnotetext{
3. La correspondència entre aquests versos fou detectada per Riquer (1955). En l'edició de Piaget (1949: 54), el poema de Chartier és editat com una cançó, i així l'identifica també Riquer (1955); Laidlaw (1974: 384-385) edita un rondell, que és la forma original del poema. Aquí reprodueixo, però, l'edició de Piaget, ja que el text del seu manuscrit base és més proper als versos de March que no el que edita Laidlaw.
} 
a La glòria d'amor:
$[. .$.$] infants$
[e] mils cantant, a mon avis, que [no] angels de Paradis una canço de dol e plors qui.m parague del «angoxos»
$[\cdots]$
lexe finar «cuer doloros»,
qui es la fi del «angoxos»

(vv. 187-191 i 198-199; Heaton 1916: 59)

La cançó «de l'angoixós» també és citada en dues ocasions pel poeta castellà Juan de Tapia, que estigué al servei d'Alfons el Magnànim a Nàpols des de 1435 fins a la mort del rei el 1458:

Mis ojos dexo a los vuestros

por que los podáis mirar,

que por amores siniestros

vos los fuisteis a matar.

Pues la muerte daes a nos,

la vida se nos destierra,

cantando «de l'anguxós»

faré fin sobre la tierra.

(Juan de Tapia, XVII, vv. 5- I2; Giuliani 2004:

9l)

\section{Alcaide triste cuitado}

con la mi negra vandera,

por vuestra crüeldat fiera,

moriré de enamorado;

cantando «De languxós»

será mi fin si no acorre

Dios e vos en esta torre

con mis lágrimas por vos.

(Juan de Tapia, XIX, vv. 29-36; Giuliani 2004: 96)

Whetnall ha identificat de manera definitiva la «cançó de l'angoixós» amb la versió musical de la balada de Christine de Pizan. La composició de Gilles Binchois fou molt coneguda i influent, se'n feren diverses versions i fou adaptada per a la veu tenor d'una missa (Whetnall 2005: 185). La balada original de Christine de Pizan, amb tres estrofes i tornada, s'ha transmès als cançoners musicals només amb la primera cobla:

Deuil engoisseux, rage desmesurée,

Grief desespoir, plein de forsennement,

Langour sanz fin, vie maleürée

Pleine de plour, d'engoisse et de tourment,
Cuer doloreux qui vit obscurement,

Tenebreux corps sus le point de perir,

Ay, sanz cesser, continuellement;

Et si ne puis ne garir ne morir.

(Christine de Pizan, Les Cent Ballades, VI, vv. I-8; Roy 1856-1932: I, 7)

Com assenyala Whetnall (2005: 185-187), hi trobem el «cuer doloreux» que esmenta Rocabertí, que són les primeres paraules de la segona secció musical de la peça, la que inicia el desenllaç final («lexe finar "cuer doloros", qui es la fi del "angoxos" $\gg)$. Dos elements més ajuden a identificar la referència de Bernat Hug de Rocabertí: d'una banda, observem que era,

\section{Estructura musical del rondell: Triste plaisir et doloureuse joye d'Alain Chartier}

Al marge del poema, les lletres en majúscula indiquen les seccions idèntiques en text $i$ en música, i en minúscula les seccions amb la mateixa música però amb text diferent. Els dos primers versos del refrany, la secció $A$, era la que més vegades es repetia:

A Triste plaisir et doloureuse joye, aspre doulceur, resconfort ennuyeux,

B ris en plourant, souvenir oublïeux, macompaignent combien que seule soye.

a Embuschez sont, affin qu'on ne les voye, dedans mon cuer en l'ombre de mes yeulx

A triste plaisir et doloreuse joye, aspre doulceur, resconfort ennuyeux.

a C'est mon tresor, ma part et ma monjoye, de quoy Dangier est sur moy envïeux.

b Bien le sera s'il me voit avoir mieulx, quant il a dueil de ce qu'Amours m'envoye.

A Triste plaisir et doloreuse joye, aspre doulceur, resconfort ennuyeux,

B ris en plourant, souvenir oublïeux, macompaignent combien que seule soye. 
efectivament, una «cançó de dol e plors» («pleine de plour»»); de l'altra, és cantada per un cor, la qual cosa podria indicar, tot i que no necessàriament, que la cançó estava destinada a la interpretació polifònica. Així doncs, una de les peces de Les Cent Ballades de Christine de Pizan era coneguda a la Corona d'Aragó amb la música.

La glòria d'amor de Bernat Hug de Rocabertí és una obra d'una riquesa extraordinària: en aquest llarg poema de caràcter al legòric, clar exponent del gènere del «jardí d'amor»o «infern d'enamorats», s'hi combinen la influència italiana amb referents francesos i la tradició poètica pròpia, bàsicament Ausiàs March. Cal afegir que l'obra és plena de referències musicals - danses, cançons $\mathrm{i}$ instruments-amb les quals segurament Rocabertí reproduïa l'ambient cortesà real de l'època. A més de la «cançó de l'angoixós», l'autor fa al lusió a una altra cançó francesa:

E dins aquell Affrico viu sonave ab gran delit un clavisin molt fi; e lo so d'ell «Cuer ye sospir» semblave.

(Bernat Hug de Rocabertí, La glòria d'amor, vv. I.I30-I.I32; Heaton 1916: 86)

Pagès (1936: 53) constatà l'existència d'una peça de Gilles Binchois que comença «Se je souspire», i podem afegir que una chanson balladée de Guillaume de Machaut també s'inicia amb «Se je souspire» (Chichmaref 1909: II, 623). Amb tot, sembla més segur relacionar la composició que cita Rocabertí amb el lai anònim De cuer, je souspire, segurament del segle XIV, una peça important en la història de la música perquè es considera el lai amb notació musical transmès més tardanament (Wright 1974: 310-31I). Aquest lai, de transmissió única, es troba en un manuscrit copiat pels volts de 1420 a Borgonya (Dijon, Bibliothèque publique, ms. 2837), del qual s'han conservat només dos bifolis (vuit pàgines), reutilitzats com a fulls de guarda d'un incunable (Wright 1974: 306). El lai devia tenir prou fama i difusió, perquè a mitjan segle XV serví de base -igual que la balada de Christine de Pizanper a una missa. La missa Du cuer je souspier, composta c.1450, es recull com a anònima en un manuscrit (Trento, Castello del Buon Consiglio, ms. TR89), i el lai De cuer je souspire n'és la font del tenor (Wright 1974: 310). D'altra banda, Pagès (1936: 52-53) suggerí que el Cuer, ye soupir de La glòria d'amor, com que és interpretat pel personatge Affrico, del Ninfale Fiesolano de Boccaccio, devia ser conegut també a Itàlia. La conjectura de Pagès podria afermar-se si identifi-

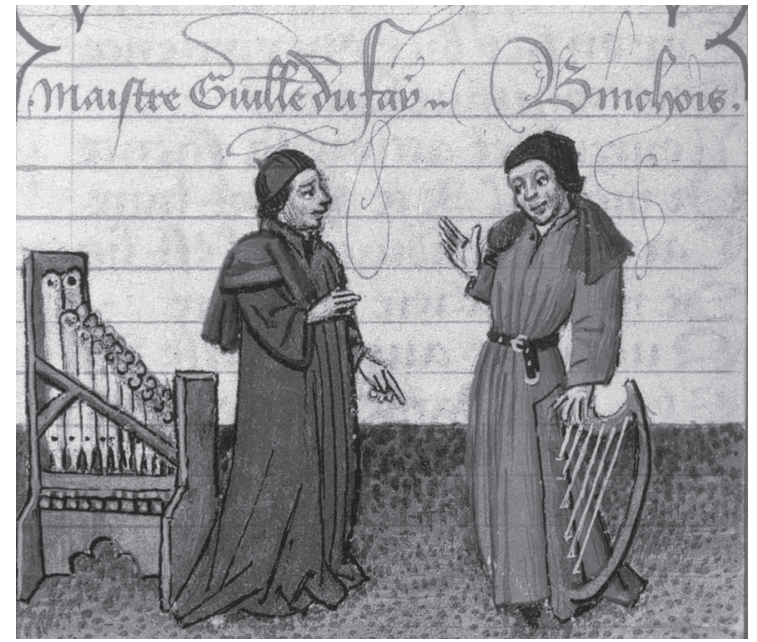

A la dreta: Gilles Binchois, amb una arpa; a l'esquerra: Guillaume Dufay, al costat d'un orgue positiu (Le Champion des dames, de Martin Le Franc: París, Bibliothèque Nationale, ms. fr. I2476, f. 98; 1442).

quem la composició amb el lai De cuer je souspire, ja que el manuscrit de Trento és un testimoni important de música sacra europea copiat al nord d'Itàlia.

Es pot plantejar la hipòtesi, doncs, que el Cuer, ye sospir de Rocabertí fos una versió del lai De cuer, je souspire: d'una banda, el lai destacava per la música (d'aquí que s'adaptés per a una missa), cosa que encaixa amb la manera com es presenta Cuer, ye sospir a La glòria d'amor, on la composició no és cantada sinó interpretada amb un clavecí i el narrador en reconeix «lo so»; d'altra banda, el clavecí, un instrument voluminós de teclat de cordes pinçades, ens indicaria que es tractava d'una versió adaptada al clavecí d'aquest lai. Al segle $\times \mathrm{V}$, el clavecí era un instrument de luxe, poc corrent, que només es podien permetre les corts més selectes. Rocabertí devia haver vist i sentit tocar el clavecí. En tenia un, per exemple, Carles d'Aragó, príncep de Viana: segons un document de 1442, l'infant Carles va comprar a un argenter uns orgues, un llaüt i un clavecí (Dalmases 1992: II, 85). Els contactes documentats del príncep de Viana amb Rocabertí, però, són posteriors a la mort d'Alfons el Magnànim i comencen el 1459 quan Carles d'Aragó s'establí a Sicília (Bassegoda 2006). Rocabertí podria haver sentit tocar el clavecí en una altra cort.

En aquest breu recorregut per la poesia i la música franceses a la Corona d'Aragó, queden per resoldre encara molts interrogants. Per exemple, no s'ha contemplat mai seriosament la possibilitat que les balades i els lais dels poetes catalans fossin cantats, principalment perquè no se n'ha conservat 


\section{De cuer je souspire}

a. Anon., Missa Du cuer je souspier, Trent 89 , fol. $282^{\circ}$
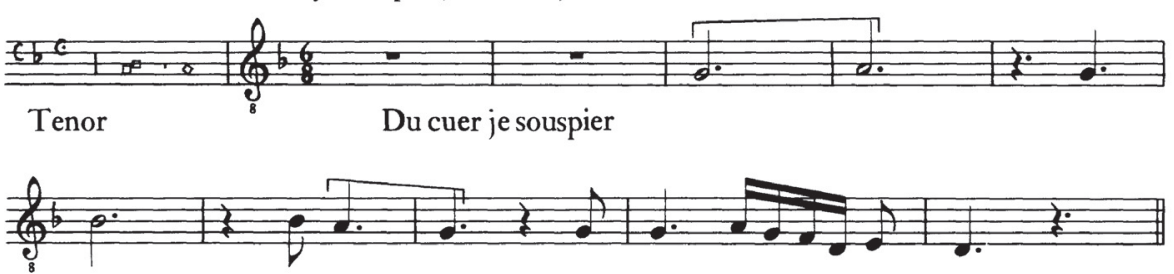

b. Anon., "De cuer je soupire," Dijon 2837 , fol. I
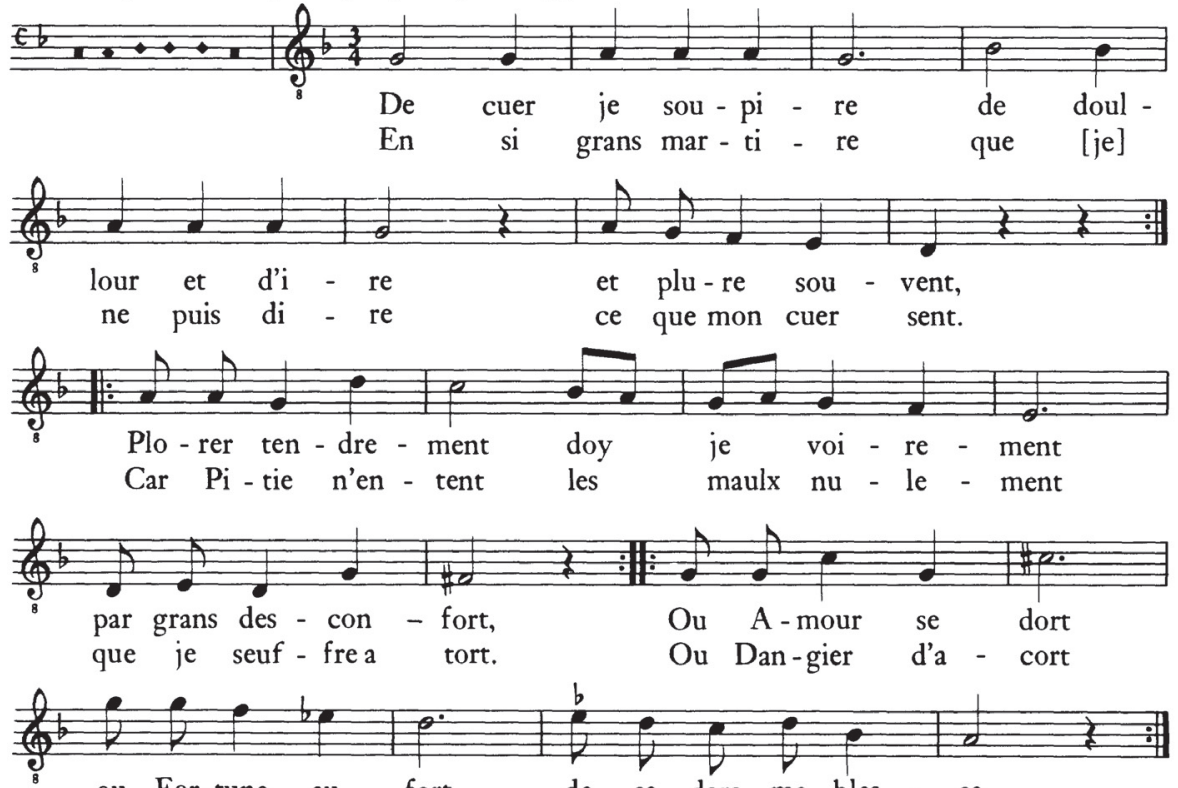

ou For-tune au fort de se dars me bles - se,

est con-tre mon sort ou cuer ma mais-tres - se.

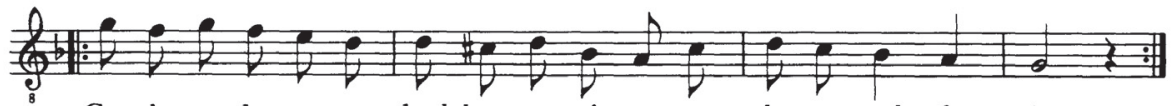

Carplus ay des-tres-se doul-lour et tris-tes-se plus me veult fu - ir;

J'u-ze ma jo-nes-se sans a-voir li - es - se en mou-rant mar - tir.
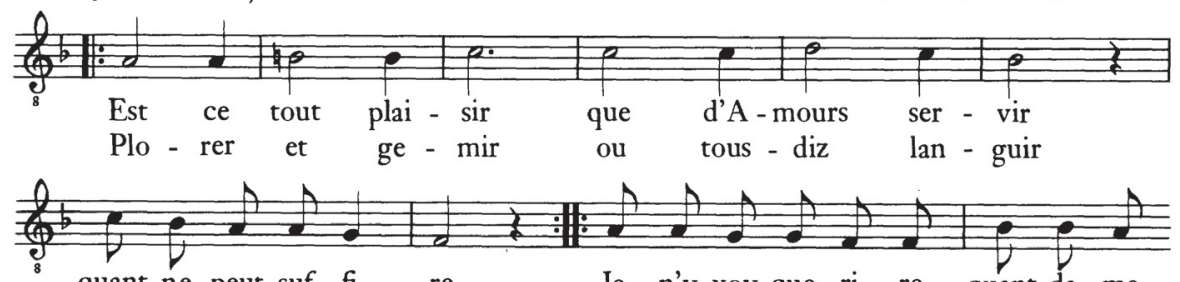

quant ne peut suf - fi - re Je n'y voy que ri - re quant da-me
ce des maulx le pi - re. ce des maulx le pi - re.

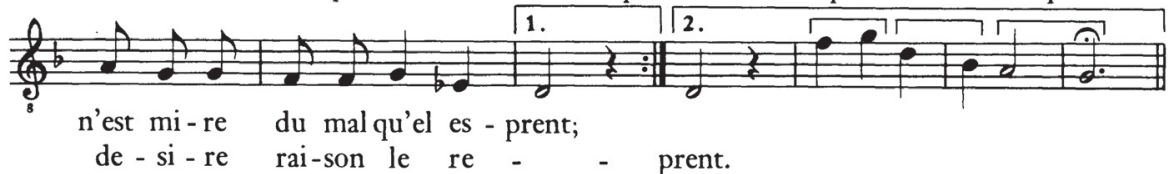

Transcripció del tenor de la missa Du cuer je souspier (Trento, Castello del Buon Consiglio, ms. TR89) i del lai De cuer je souspire (Dijon, Bibliothèque publique, ms. 2837) (Wright 1974: 312). 
la música. Aquest argument pesa com una llosa sobre un indici clar que almenys alguns poemes tenien música. Em refereixo a la figura de Jordi de Sant Jordi, un dels poetes que adaptà les formes fixes musicals franceses i que, segons el testimoni del marquès de Santillana, que el coneixia bé perquè coincidiren tots dos al servei d'Alfons el Magnànim, «conpuso asaz fermosas cosas, las quales él mesmo asonava ca fue músico exçellente» (Prohemio, Rohland 1997: 22). El testimoni fiable del marquès de Santillana ens permet argumentar que alguns poemes de Jordi de Sant Jordi tenien música i es cantaven, com a mínim la Dansa e escondit («Tant es li mals que $m$ fayts soffrir»), la balada Lo canviador («Pus que tan bé sabetz de cambiar») i el lai Los enuigs («Enuig, enemich de jovent»). Sobre les primeres adaptacions de formes fixes franceses, les d'Andreu Febrer i Gilabert de Pròixida, fa estrany que, en una cort concorreguda pels millors músics de l'època, es concebessin només com a poemes escrits. Res no ens impedeix de suposar que els poemes amb estructura musical haguessin

\section{Pere Torroella}

El músic Juan Cornago, documentat des de I 452 a la capella d'Alfons el Magnànim a Nàpols (Rodríguez Risquete 2003: LII), féu una versió musical del poema de Pere Torroella Yerra con poco saber, conservada en dos manuscrits de procedència napolitana (Gerber 1984: xxvixxvii i 56-57; per al poema de Torroella, vegeu Rodríguez Risquete 2003: LII i 247-249). A més, al manuscrit de Trento que conté la missa Du cuer je souspier (Trento, Castello del Buon Consiglio, TR89), hi ha copiada també una peça religiosa, Ex ore tuo, basada en la versió de Yerra con poco saber de Cornago.

D'altra banda, el poema Pues servicio vos desplace, transmès com a anònim però atribuïble a Pere Torroella, fou musicat per Enric, probablement el mateix Enric documentat com a músic de la capella del príncep de Viana (Rodríguez Risquete 2003: LXII). Pel que fa a l'obra en català de Pere Torroella, hi ha indicis per pensar que el poema Pus no us desment ignorança l'entendre, el primer sonet en català conservat, anava acompanyat de música (Rodríguez Risquete 2003: LII, 91-93). pogut ser objecte de la versió d'algun compositor: la figura del músic-poeta tendeix a desaparèixer a partir de la generació post-Machaut, però molts músics treballen amb els textos dels poetes, com ara Gilles Binchois. Aquest no era un fenomen exclusivament francès, $i$ en tenim un exemple en la versió que va fer el músic Juan Cornago, al servei d'Alfons el Magnànim, del poema de Pere Torroella Yerra con poco saber.

Des de l'època de Pere el Cerimoniós, i sobretot amb Joan I, la poesia francesa tingué un pes important a la cort d'Aragó per les relacions dels seus monarques amb la noblesa francesa, a través de la qual circulaven els llibres, i sobretot per la música: la cort d'Aragó no rep només l'influx de la música francesa, sinó que és un dels nuclis principals de conreu de l'Ars subtilior. La presència de músics francesos continuà amb Martí I i a Sicília amb Martí el Jove, ja que alguns dels compositors de Joan I estan documentats també al servei dels seus successors. Amb Alfons el Magnànim la música tingué una importància extraordinària, i la seva capella a Nàpols fou una de les més importants i espectaculars d'Europa. El príncep Carles de Viana també envoltà la seva cort de música: sabem que comprava instruments luxosos, que encarregava llibres de cant per a la seva capella (Cruells 1932: 92), i una secció del cançoner conegut com a $N$ (Barcelona, Biblioteca de l'Ateneu, ms. I) que es relaciona amb l'entorn proper al príncep conté peces d'origen musical (Rodríguez Risquete 2009); a més, diversos documents atesten les vetllades de música i dansa que organitzà en la seva estada a Sicília (Rodríguez Risquete 2009).

La glòria d'amor de Rocabertí demostra que la música era cantada, com a tot Europa, en francès, i que a la Corona d'Aragó es coneixien les composicions de moda de la cort de Borgonya, el centre musical més influent a mitjan segle $x \mathrm{~V}$. En aquest sentit, les cançons citades per Francesc de la Via, Bernat Hug de Rocabertí i Juan de Tapia indiquen que els poetes del segle $\times v$ estaven plenament imbuiits de l'ambient musical de les seves corts. A més, la música es perfila com el canal de difusió d'alguns poetes francesos, tal com exemplifiquen la balada de Christine de Pizan i probablement alguns rondells d'Alain Chartier. Si es vol determinar amb precisió la influència francesa en la poesia catalana, no es pot prescindir de les composicions musicals, altrament les conclusions serien parcials. Cal conèixer els textos que llegien els poetes catalans, però també la música que escoltaven. 


\section{Bibliografia citada}

AlbernI, Anna, 2005: «Gilabert de Pròixida, un poeta cortesà al servei del casal d'Aragó», Actes del X Congrés de l'Associació Hispànica de Literatura Medieval (Alacant 2003), ed. Rafael Alemany, Josep Lluís Martos i Josep Miquel Manzanaro, Alacant: Institut Interuniversitari de Filologia Valenciana, III, 227-240.

AlbernI, Anna, 2007: «El Procés de Francesc de la Via, una nota de societat gironina de l'any |406», Actes del Tretzè Col/loqui Internacional de Llengua i Literatura Catalanes, ed. Sadurní Martí et al., Barcelona: Publicacions de l'Abadia de Montserrat, III, 82-I0I.

BASSEGODA, Enric, 2006: «Fra Bernat Hug de Rocabertí, comanador d'Alfambra i de Montsó», Actes del Tretzè Col/loqui Internacional de Llengua i Literatura Catalanes, ed. Sadurní Martí et al., Barcelona: Publicacions de l'Abadia de Montserrat

CABRÉ, Lluís, 1986: «"Los enuigs" de Jordi de Sant Jordi i l'adaptació del lai líric a la poesia catalana medieval», Estudis de literatura catalana en honor de Josep Romeu i Figueras, ed. Lola Badia i Josep Massot i Muntaner, Barcelona: Publicacions de l'Abadia de Montserrat, I, I83-206.

CABRÉ, Lluís, 1987: «El conreu del lai líric a la literatura catalana medieval», Llengua \& Literatura, 2, 67-132.
CABRÉ, Lluís, 2007: «Andreu Febrer, fabbro i lector», From the Cancioneiro da Vaticana to the Cancionero general: Studies in Honour of Jane Whetnall, ed. Alan Deyermond i Barry Taylor, Londres: Queen Mary, University of London, 103-||4.

Chichmaref, V. (ed.), 1909: Guillaume de Machaut, Poésies lyriques, París: Champion, 2 vols.

Cruells, Manuel, 1932: «Alguns documents sobre la vida cultural i literària de Carles de Viana», Estudis Universitaris Catalans, 17, 86-94.

DALMASES, Núria de, 1992: Orfebreria catalana medieval, Barcelona: Institut d'Estudis Catalans, 2 vols.

Fallows, David, 2000: «Binchois and the Poets», Binchois Studies, ed Andrew Kirkman \& Dennis Slavin, Oxford: Oxford University Press, 199-215.

Gerber, Rebecca L. (ed), 1984: Johannes Cornago, Complete Works, Madison: A-R Editions.

GIULIANI, Luigi, 2004: Juan de Tapia, Poemas, Salamanca: Ediciones Universidad de Salamanca.

Gómez Muntané, Maricarmen, 1979: La música en la casa real catalano-aragonesa 1336-1442, Barcelona: Bosch, 2 vols.

Gómez MuntanÉ, Maricarmen, 2009: «Trebor a Navarra i Aragó», Mot so razo, 8, 7-I5.
Heaton, H. C., 1916: The glòria d'amor of fra Rocabertí, Nova York: Columbia University Press.

LAIDLAW, J.C., 1974: The Poetical Works of Alain Chartier, Cambridge: Cambridge University Press.

PACHECO, Arseni (ed.), 1997: Francesc de la Via, Obres, Barcelona: Quaderns Crema.

PAgès, Amadée, 1936: La poésie française en Catalogne du XIIIe siècle à la fin du xve, Tolosa - París: Privat \& Didier.

Parera, Raquel, 2006: «La versió d'Andreu Febrer de la Commedia de Dante: estudi del manuscrit i edició de l'Infern, |-X|»», Treball de Recerca, Bellaterra: Universitat Autònoma de Barcelona.

PIAGET, Arthur (ed.), 1949: Alain Chartier, La Belle Dame sans mercy et les poésies Lyriques, Lille Ginebra: Giard \& Droz.

RIALC Repertorio informatizzato dell'antica letteratura catalana (Università di Napoli Federico II), http://www.rialc.unina.it.

RIERA, Jaume, 2008: «Una cançó de despit contra el rei Martí», Mot so razo, 7, 34-4l.

Riquer, Martí de, 1955: «Alain Chartier y Ausiás March», Revista de Filología Española, 39, 336-338.

RodríGuez RISQUete, Francisco, 2003: «Vida y obra de Pere Torroella», Tesi doctoral, Girona: Universitat de Girona. 
Rodríguez Risquete, Francisco, 2009: «El cançoner de l'Ateneu (Biblioteca de l'Ateneu de Barcelona, ms. I)», Translatar i transferir. La transmissió dels textos i el saber (1200-1500). Actes del primer col loqui internacional del grup Narpan, Santa Coloma de Queralt: Obrador Edèndum.

Rodríguez RISQuete, Francisco (ed.), en premsa: Pere Torroella, Obra completa, Barcelona: Barcino, 2 vols.

RoHLAND, Regula (ed.), 1997: Marqués de Santillana, Comedieta de Ponza sonetos, serranillas y otras obras, Barcelona: Crítica.
Roy, Maurice (ed.), 1886-1896: Oeuvres poétiques de Christine de Pisan, París: Didot, 3 vols.

TORRó, Jaume (ed.), 1996: Romeu Llull, Obra completa, Barcelona: Barcino.

TORRÓ, Jaume, 2007: [ressenya de] «Jordi de Sant Jordi, Poesies, ed. Aniello Fratta ("Els nostres clàssics", col lecció B, núm. 26), Barcelona, Barcino, 2005», Arxiu de Textos Catalans Antics, 26, 822-826.

WHETNALL, Jane, 2005: «"Veteris vestigia flammae": a la caza de la cita cancioneril»», I canzonieri di Lucrezia/Los cancioneros de Lucrecia. Atti del convegno internazionale sulle raccolte poetiche iberiche dei secoli XV-XVII. Ferrara, 7-9 ottobre 2002, ed. Andrea Baldissera i Giuseppe Mazzocchi, Pàdua: Unipress, 179-192.

WRIGHT, Craig, 1974: «A fragmentary manuscript of early 15th-century music in Dijon», Journal of the American Musicological Society, 27, 2, 306-3I5.

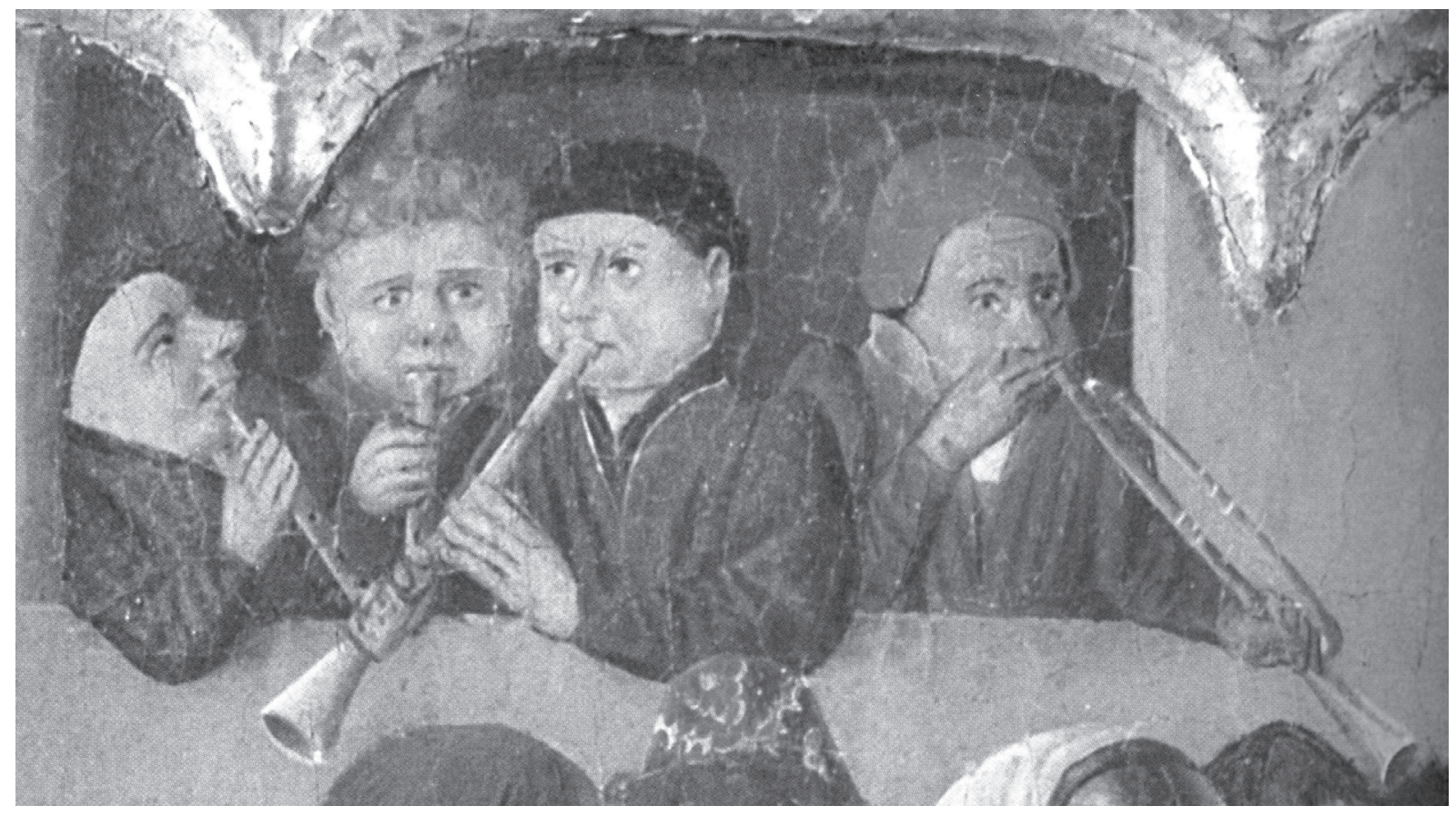

Ministrers amb tres xeremies i una trompeta tocant al Banquet d'Herodes (taula de de Joan Figuera, de mitjan segle xv. Barcelona, MNAC). 